\title{
Descriptive study of cough, wheeze and school absence in childhood
}

\author{
Iolo J M Doull, Andrew A Williams, Nicholas J Freezer, Stephen T Holgate
}

\begin{abstract}
Background - Respiratory symptoms such as cough and wheeze are associated with significant morbidity, including school absenteeism.

Methods - A respiratory questionnaire was sent to the parents of all 5727 children aged 7-9 years of age registered with 95 general practitioners in the Southampton area to determine (a) the prevalence of asthma, cough and wheeze, (b) the effects of respiratory symptoms on school absenteeism, and (c) the use of anti-asthma medication. Results - A total of 4830 parents replied (response rate $86 \%$ ). The 12 month prevalence of wheeze in the absence of cough was $5 \cdot 5 \%$, cough in the absence of wheeze was $10 \cdot 0 \%$, and $7 \cdot 6 \%$ reported cough and wheeze; $15 \cdot 2 \%$ of children had been diagnosed as asthmatic by their general practitioner. Of the 4830 who replied, $12 \cdot 7 \%$ were receiving bronchodilators, $0.6 \%$ xanthine derivatives, $1 \cdot 7 \%$ sodium cromoglycate, and $4 \cdot 1 \%$ inhaled corticosteroids. In all, $348(7 \cdot 2 \%)$ children had missed more than five days of schooling in the preceding year for respiratory symptoms, while 43 children $(0.9 \%)$ had missed more than 20 days of schooling in the preceding year. Of the children who had missed more than five days of schooling, $43 \%$ reported cough and wheeze, $33 \%$ cough alone, and $16 \%$ wheeze alone in the preceding year. Compared with children who coughed, those who wheezed were significantly more likely to be diagnosed as asthmatic and to be receiving bronchodilators or inhaled corticosteroids.

Conclusions - In this study, cough was the most frequently reported symptom amongst children missing more than five days of schooling per year.

(Thorax 1996;51:630-631)
\end{abstract}

University Medicine, Level D, Centre Block, Southampton General Hospital,

Southampton, UK

I J M Doull

A A Williams

N J Freezer

S T Holgate

Correspondence to: Dr I Doull, Paediatric Intensive Care Unit, Hospital for Sick Children, Great Ormond Street, London WC1N 3JH, UK.

Received 23 October 1995 Returned to authors 20 January 1996 Revised version received 9 February 1996 Accepted for publication 19 February 1996 onstrated the pernicious effect of undertreatment of respiratory symptoms, especially on school attendance..$^{1-3}$ School absenteeism is associated with significantly impaired social, psychological, and educational adjustment. ${ }^{2}$

Reported wheeze has frequently been used as a surrogate marker for asthma. ${ }^{1}$ In some children, however, the only manifestation of asthma is chronic cough in the absence of wheeze. ${ }^{4}$ These children show similar abnormalities of lung function and bronchial responsiveness to those children who manifest asthma in the form of wheeze, and show a similar response to anti-asthma medication. ${ }^{4}$ At present the nature of chronic cough in relation to the diagnosis of asthma and its appropriate treatment remains unclear. ${ }^{5}$

The aims of this study were threefold: to measure the population prevalence of reported asthma, cough and wheeze in 7-9 year old children; to estimate school absenteeism attributable to respiratory symptoms; and to record the use of anti-asthma medication.

\section{Methods}

The parents of all children aged between 7 and 9 years of age registered with 95 general practitioners located across the Southampton area were sent a questionnaire based on questions employed in previous cross sectional studies. The questionnaire was simple and enquired about respiratory symptoms, school absence, diagnosis of asthma, and anti-asthma treatment in the child. Wheeze was assessed by the question: "In the last 12 months has your child ever had an attack of wheezing (by wheezing I mean noisy breathing with a whistling sound coming from the chest, not the throat)", and parents were asked to quantify the frequency. Cough was assessed by the question: "In the last 12 months has your child seemed to cough more (or get more coughs) compared with other children". Parents were asked to quantify "In the last 12 months how many days has your child had off school with any chest symptom (e.g. cough, wheeze, breathlessness, chest tightness)?" into 0 days, 1-5 days, 6-20 days, and more than 20 days. Finally, parents were asked whether "a doctor has ever said your child has asthma", and asked to select from a list of proprietary and generic names of anti-asthma medication that their child had received in the preceding 12 months. Questionnaires were sent in May 1991 and, if there was no reply within four weeks, a reminder was sent.

Group comparisons utilised the $\chi^{2}$ test with Yates' correction or Fisher's exact test for small groups. The study was approved by the Southampton Hospitals joint ethics committee.

\section{Results}

Questionnaires were sent to the parents of 5727 children. Eighty five were returned unanswered as the family had moved out of the area; 3586 (63.6\% response) replies were received within four weeks with a further 1244 replies after the 
Number of days of schooling missed in previous 12 months due to chest problems

\begin{tabular}{llcccc}
\hline $\begin{array}{l}\text { No. of } \\
\text { days }\end{array}$ & $\begin{array}{l}\text { No. of } \\
\text { children }\end{array}$ & $\begin{array}{l}\text { \% of } \\
\text { total }\end{array}$ & $\begin{array}{l}\text { \% diagnosed } \\
\text { asthmatic }\end{array}$ & $\begin{array}{l}\text { \% reporting } \\
\text { cough }\end{array}$ & $\begin{array}{l}\text { \% reporting } \\
\text { wheeze }\end{array}$ \\
\hline 0 & 3381 & $70 \cdot 0$ & $7 \cdot 4$ & $5 \cdot 6$ & $4 \cdot 3$ \\
$1-5$ & 1028 & $21 \cdot 3$ & 30 & $38 \cdot 2$ & $27 \cdot 9$ \\
$6-20$ & 305 & $6 \cdot 3$ & 49 & $72 \cdot 5$ & $55 \cdot 7$ \\
$>20$ & 43 & $0 \cdot 9$ & 51 & $91 \cdot 0$ & $65 \cdot 1$ \\
\hline
\end{tabular}

reminder, giving a total of 4830 replies $(85 \cdot 6 \%$ response).

Of the 4830 replies, 2508 were for boys $(52 \cdot 2 \%)$ and $2293(47 \cdot 8 \%)$ for girls, with 29 unclassified. The mean (SD) age of all the children was $8.04(0.86)$ years. $5 \cdot 5 \%$ of the children were reported to have had a wheezing attack but had not coughed more than others in the previous 12 months, $10.0 \%$ coughed more than others but had no history of wheeze in the previous 12 months, and $7 \cdot 6 \%$ reported both cough and wheeze in the last 12 months. Of those who wheezed $69 \%$ had been diagnosed as asthmatic by their general practitioners, while $46 \%$ of those who coughed had been diagnosed asthmatic. In all, $15 \cdot 2 \%$ of children had received a diagnosis of asthma from their general practitioner.

Of the 4830 replies, $12 \cdot 7 \%$ of the children were receiving bronchodilators, $0.6 \%$ xanthine derivatives, $1.7 \%$ sodium cromoglycate, and $4 \cdot 1 \%$ inhaled corticosteroids. A total of 348 $(7 \cdot 2 \%)$ children were reported to have missed more than five days of schooling because of chest problems in the preceding year, of whom $49 \%$ had been diagnosed as asthmatic. Forty three children $(0.9 \%)$ missed more than 20 days of schooling in the preceding year, of whom $22(51 \%)$ were diagnosed asthmatic. The frequency of school absence due to chest illness and the pattern of symptoms is shown in the table. Of the children who had missed more than five days of schooling, $43 \%$ reported cough and wheeze, $33 \%$ cough alone, and $16 \%$ wheeze alone in the preceding year. In this group of children $51 \%$ were receiving bronchodilators and $20 \%$ were receiving inhaled corticosteroids.

Although a greater proportion of children who reported cough missed more than five days of schooling than children who reported wheeze, the difference was not significant $(24 \%$ versus $\left.19 \%, \chi^{2}=1 \cdot 75, p=N S\right)$. Compared with children who reported cough, those who reported wheeze were significantly more likely to be diagnosed asthmatic $\left(\chi^{2}=94, \mathrm{p}<0.00001\right)$, and to be receiving bronchodilators $\left(\chi^{2}=76\right.$, $\mathrm{p}<0.00001)$, cromoglycate $\left(\chi^{2}=14, \mathrm{p}<0.001\right)$, xanthines $\left(\chi^{2}=9.8, \mathrm{p}<0.01\right)$, and inhaled corticosteroids $\left(\chi^{2}=35, \mathrm{p}<0 \cdot 00001\right)$.

Of the small group of 43 children who missed more than 20 days of schooling per year, $58 \%$ reported cough and wheeze, $33 \%$ cough alone, and $7 \%$ wheeze alone in the preceding year. Of these children, $49 \%$ were receiving bronchodilators and $16 \%$ were receiving inhaled corticosteroids. The probability of receiving inhaled corticosteroids was significantly greater if the child reported wheeze compared with cough (Fisher's two tailed, $\mathrm{p}=0.002$ ).

\section{Discussion}

In those children who missed more than five days of schooling per year, cough was the most common symptom. Children were more likely to be labelled asthmatic, to be receiving bronchodilators, or to be receiving prophylactic treatment if their major symptom was wheeze. Cough may be a manifestation of asthma ${ }^{4}$ but lacks specificity and may be due to other conditions. Neither atopic history nor bronchial hyperresponsiveness are helpful in distinguishing asthma in children with recurrent cough. ${ }^{5}$ The current paediatric consensus statement on asthma defines "a syndrome consisting of chronic or recurrent wheezing and/or coughing in a setting where asthma is likely". Without detailed assessment and possibly therapeutic intervention, we cannot be certain that the children with recurrent cough and school absence had asthma.

Although school absenteeism is a crude index of morbidity, it has been used as an index of undertreatment and response to treatment. ${ }^{1}$ The asthma consensus statement recommends that there "should not be excessive school absences". ${ }^{6}$ We cannot know whether anti-asthma medication would have benefited those children missing school due to either cough or wheeze. Nevertheless, only half of those children who missed more than five days of schooling per year to respiratory symptoms were receiving bronchodilators, while a fifth were receiving inhaled corticosteroids. Treatment patterns were similar in the small number of children who missed more than 20 days of schooling per year. Our findings suggest that children who report cough are less likely to be diagnosed asthmatic or to receive treatment than those who report wheeze, and suffer substantial morbidity. Cough in childhood warrants greater attention and is a potential subject for therapeutic intervention.

1 Speight ANP, Lee DA, Hey EN. Underdiagnosis and undertreatment of asthma in childhood. BMF 1983;286:1253-6. 2 Anderson HR, Bailey PA, Cooper JS, Palmer JC, West S. Morbidity and school absence caused by asthma and wheezing illness. Arch Dis Child 1983;58:777-84.

3 Hill RA, Standen OJ, Tattersfield AE. Asthma, wheezing and school absence in primary schools. Arch Dis Child 1989; 64:246-51.

4 Cloutier MM, Loughlin GM. Chronic cough in children; a manifestation of airway hyperreactivity. Paediatrics 1981; 67:6-12.

5 McKenzie S. Cough - but is it asthma? Arch Dis Child 1994; 70:1-2.

6 Asthma: a follow up statement from an international paediatric asthma consensus group. Arch Dis Child 1992;67: 240-8. 